\title{
On the Reduction Degradation of Lime Sinter*
}

\author{
By Minoru SASAKI, ${ }^{* *}$ Tsuneo ENOKIDO, ${ }^{* *}$ and Shin-ichi KONDO**
}

Recently, it has been reported that the reduction degradation of lime sinter originates in the hematite grains of a characteristic shape., ${ }^{1,2)}$ In the present work, the relationship between the microcrack formation and the composition of such grains was investigated.

Thin specimen of about $1 \mathrm{~mm}$ thick was sliced from industrial sinter. After uniformity of the structure of the specimen was confirmed by microscopic observation, it was reduced for $15 \mathrm{~min}$ at $500^{\circ} \mathrm{C}$ with $30 \% \mathrm{CO}$ $70 \% \mathrm{~N}_{2}$ mixture. Then, a very thin polished section (5 to 6 microns thick) of the slightly reduced specimen was prepared for microscopic observation with both reflected and transmitted lights.

An outstanding characteristic of such hematite grains at the early stage of reduction is shown in Photo. 1 (1). It is observed that wedge-shaped magnetite, starting from a pre-existing crack, penetrate into a characteristic hematite grain and extends to the neighbouring grain. The mechanism of the magnetite formation may be explained as follows. Microcracks might have generated prior to the magnetite formation in a characteristic hematite grain. The expansion force caused by the magnetite formation in the neighborhood of the microcrack would act as a concentrated stress at the top of the microcrack and induce further growth of the crack.

Then the hematite grain in the sample sinter was examined. Photo. 1 (2) shows the characteristic grains having close connection with the degradation. Transmission color of the grain is turbid deep red. Extinction is not observed. These facts suggest that fine precipitates are dispersed in the grain.

Results of X-ray microanalysis of the hematite grain and the coexisting phases are listed in Table 1. Subconstituents such as $\mathrm{Al}_{2} \mathrm{O}_{3}, \mathrm{TiO}_{2}$, and $\mathrm{MnO}$ in the hematite supposedly compose the precipitates. It is considered that multi-component magnetite grain, releasing $\mathrm{CaO}$ and $\mathrm{MgO}$, transformed to the hematite under the favorable condition for grain growth, and that remained minor components constitute the precipitates in the grain. The stress in the grain caused by the precipitates formed during cooling might give rise to the microcrack in the grain at the earlier stage of reduction.

Then, let us consider the formation of the pre-existing crack in the multi-component hematite grain. The silicate glass surrounding the hematite grain is poor in $\mathrm{CaO}$ and rich in $\mathrm{SiO}_{2}$, as illustrated in Table 1. It can be estimated that the composition of "micro-

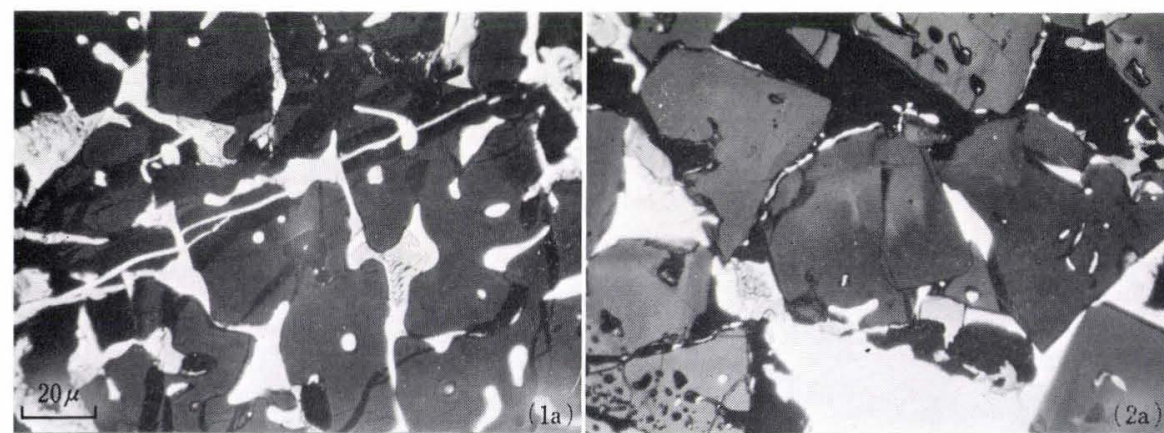

(1) Slightly reduced

(2) Before reduction

(a) Open nicol

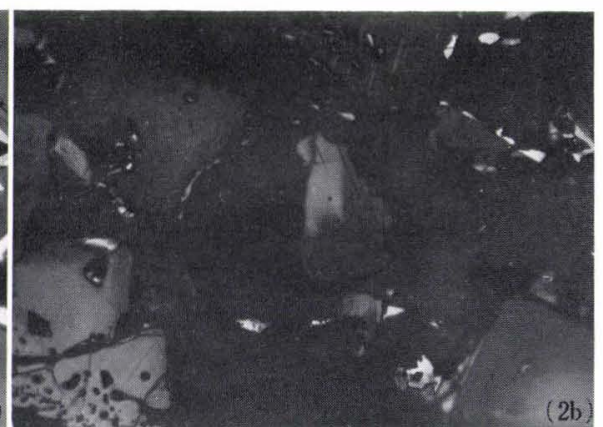

(b) Crossed nicols

Photo. 1. Microstructures of the sinter containing the characteristic hematite grains (with transmitted light)

Table 1. Results of X-ray microanalysis

\begin{tabular}{|c|c|c|c|c|c|c|c|c|c|}
\hline \multirow{2}{*}{ Analyzed phase } & \multicolumn{9}{|c|}{ As oxide $(\%)$} \\
\hline & $\mathrm{Fe}_{2} \mathrm{O}_{3}$ & $\mathrm{FeO}$ & $\mathrm{CaO}$ & $\mathrm{MgO}$ & $\mathrm{MnO}$ & $\mathrm{TiO}_{2}$ & $\mathrm{Al}_{2} \mathrm{O}_{3}$ & $\mathrm{SiO}_{2}$ & Sum \\
\hline m.* magnetite & $\begin{array}{c}\mathrm{Fe}_{3} \mathrm{O}_{4} \\
96.7\end{array}$ & - & 0.8 & 0.5 & 0.3 & 0.2 & 1.1 & - & 99.6 \\
\hline m.* hematite & 98.3 & - & - & - & 0.2 & 0.1 & 0.8 & & 99.4 \\
\hline m.* hematite & 99.1 & & - & 一 & 0.2 & 0.5 & 1.0 & & 101 \\
\hline Silicate glass coexisting with $\mathrm{m}$. hematite & - & 19.3 & 25.6 & 0.4 & 0.3 & 0.3 & 3.0 & 48.9 & 97.8 \\
\hline Silicate glass coexisting with $\mathrm{m}$. hematite & - & 13.6 & 35.4 & 2.0 & 0.4 & 0.7 & 3.8 & 44.1 & 100 \\
\hline
\end{tabular}

* m.: multi-component

* Presented at the 81st ISIJ Meeting, April, 1971, in Tokyo. Manuscript received November 15, 1971.

** Fundamental Research Laboratories, Nippon Steel Corp., Ida, Kawasaki 211. 
volume" in which multi-component hematite grains are included is different from that of ordinary " microvolumes". If there are retained "microvolumes" of extraordinary composition, uneven shrinkage will occur in sintered body during cooling and the crack formed will penetrate through the solidified "microvolume".

Pre-existing crack was also found in the hematite grain included in the large hemicalcium ferrite grain of columnar type. It is thought that the crack was primarily formed in the hemicalcium ferrite and then grew to penetrate into the included hematite grain.

The factors which have influenced upon the value of the degradation index have been expressed by investigators as functions of basicity, content of $\mathrm{Al}_{2} \mathrm{O}_{3}$ or $\mathrm{TiO}_{2}$, the total amount of hematite or magnetite and others. Obviously, they are correlated with the formation of multi-component hematite. In order to prevent the reduction degradation the amounts of the multi-component hematite should be decreased by the sufficient mixing of raw materials and by adopting a preferable heating pattern in sintering process.

\section{REFERENCES}

1) K. Sugawara and K. Sato: Tetsu-to-Hagané, 55 (1969), 1107.

2) T. Inazumi, K. Nagano, and K. Kojima: International Conference on the Science and Technology of Iron and Steel, Tokyo (1970), Preprint (I), p. 32. 